\title{
Effects of Transfer Point Glucan \#300 Supplementation on Children exposed to Passive Smoking - Placebo-driven Double-blind Clinical Trials
}

\author{
Richter Josef $^{1}$, Král Vlastimil $^{1}$, Svozil Vladimir ${ }^{2}$, Rajnohova Dobiasova Lucie $^{1}$, Pohorska Jitka ${ }^{1}$, Stiborova
} Ivana $^{1}$ and Vetvicka Vaclav ${ }^{* 3}$

'Zdravotní ústav se sídlem v Ústí nad Labem, Czech Republic

${ }^{2}$ Sanatorium Edel, Zlaté Hory, Czech Republic

${ }^{3}$ University of Louisville, Department of Pathology, Louisville, KY, USA

*Corresponding author: Dr. Vetvicka Vaclav, University of Louisville, Department of Pathology, 511 S. Floyd, Louisville, KY 40202, USA, E-mail: vaclav.vetvicka@louisville.edu

Citation: Richter Josef, Král Vlastimil, Svozil Vladimir, Rajnohova Dobiasova Lucie, Pohorska Jitka, et al. (2014) Effects of Transfer Point Glucan \#300 Supplementation on Children exposed to Passive Smoking Placebo-driven Double-blind Clinical Trials. J Nutr Health Sci 1(1): 105. doi: 10.15744/2393-9060.1.105

Received Date: April 1, 2014 Accepted Date: May 16, 2014 Published Date: May 20, 2014

\begin{abstract}
In this study, we focused on the effect of $\beta$-glucan supplementation of children with chronic respiratory problems. We measured the levels of cortisol, salivary IgE and cotinine in 56 children and evaluated the effect of 30 day supplementation with $100 \mathrm{mg} / \mathrm{day}$ oral dose of yeast-derived $\beta$-glucan. Our results showed strong decrease of cotinine and cortisol levels in saliva of $\beta$-glucan-supplemented children. The increase of total salivary IgE levels in both groups was not statistically significant. The positive effects of complex curative treatment using $\beta$-glucan were accompanied by increased physical endurance and by significant reduction of negative clinical problems of affected children.
\end{abstract}

Keywords: Glucan; Children; Saliva; IgE; Cotinine; Smoking

\section{Introduction}

Lately, there has been increasing interest in the relationship between environmental contaminants and health of the population. Children are the most sensitive to environmental contaminants, mostly due to their higher ventilation, immature immune system and, compared to adult population, longer stay outside [1]. The effect of environmental pollution influences a higher sickness rate, a higher chance of respiratory infections and the rate of allergic diseases including asthma [1]. It is important to note that contaminations of the inside environment, mostly tobacco smoke, are as effective as pollution outside. The effects of passive smoking on development of allergies demonstrated by elevated levels of $\operatorname{IgE}$ at risk children population are well established. The highest level of effects of pollution is manifested in children suffering from asthma and in children with chronic respiratory problems [2]. Asthmatic children exposed to tobacco smoke have higher IgE levels, which are caused not only by genetic disposition, but also indirectly by higher penetration of allergens through damaged mucosa [2]. Clinical manifestations of allergies, asthma and chronic respiratory diseases are further influence by living close to roads with high traffic. Nitrogen oxides and most of all nanoparticles present in exhaust fumes increase clinical problems based on suppression of immunity [3-5]. Monitoring of the effects of these stress factors by evaluation of levels of salivary cortisol offers important information about the relationship between environmental stress and actual the health quality of children. Both aerial and food allergens can serve as triggers of stress reaction [6]. The intensity of stress reaction is influenced by individual sensitivity. Allergic population, asthmatics and people with respiratory allergy have higher levels of salivary cortisol [6,7]. Increased response of the hypothalamo-hypophyse-adrenal axis to stress was found to be higher in healthy individuals with a predisposition to allergic diseases [7]. We believe that $\beta$-glucans used in our study might influence the individual's response to the stress $[8,9]$.

$\beta$-Glucan's role as a biologically active immunomodulator has been well documented for over 50 years. Interest in its immunomodulatory effects was initially raised by experiments that showed that a crude yeast extract stimulated macrophages via activation of complement system [10]. Subsequent work identified the immunoactive component as $\beta$-1,3-D-glucan [11]. Numerous publications (currently more than 5,000 studies) have shown that $\beta$-glucans, either soluble or particulate, exhibit anti-bacterial, anti-cancerous, anti-infectious and anti-stress activities (for review see [12-14]). 
In order to better evaluate the complex effects of sanatorium conditions of glucan-supplemented children, we added not only evaluation of some immunological parameters, but also clinical evaluation and functional Six Minute Walk Test (6 MWT), which is valuable test for measuring reaction to physical endurance [15]. Our present study reports significant beneficial effects of addition of glucan.

\section{Materials and Methods}

\section{Protocol}

The same protocol that was previously described [16-18] was used throughout this study. Briefly, a randomized, double-blind, placebo-controlled trial compared $\beta$-glucan \#300 and placebo in children. Sixty children from the Sanatorium for respiratory diseases EDEL Czech Republic were enrolled in the 4-week trial and 56 were used. The reason for exclusion was leaving the Sanatorium prematurely for non-medical reasons. The clinical trial was conducted at the Sanatorium EDEL (Zlate Hory, Czech Republic) and the study was approved by the Ethics committees of the Public Health Institute and Sanatorium EDEL. This study was performed in agreement with Helsinki declaration (revised version 2000.09.01) and was in full compliance with the rules of for clinical testing in the Czech Republic. Parental consent was given in all cases.

Subjects were randomly assigned to groups which were blinded to intervention. During the intervention period, the subjects consumed $100 \mathrm{mg} / \mathrm{d}$ of $\beta$-glucan or placebo. Both glucan and placebo capsules looked identical. Subjects were routinely evaluated by the medical staff. Four patients were excluded from the study, due to either an abbreviated stay in the sanatorium or due to a shortened stay based on the parent's request.

\section{Glucan}

Yeast-derived insoluble Glucan \#300 (>85\% dry w/w basis) was purchased from Transfer Point (Columbia, SC, USA). This glucan contains $96 \%$ carbohydrates and $2.1 \%$ proteins. Neutral sugar analysis confirmed $91.3 \%$ glucose and $8 \%$ mannose.

\section{Quality of environment}

The quality of environment was measured at the place of residence and at the Sanatorium EDEL by testing levels of sulphur dioxide, nitrogen oxide and particles of sizes PM 2.5 and PM 10. Overall meteorological conditions were based on countrywide net of atmosphere monitoring stations. Levels of pollen particles were also measured both at the place of residence and Sanatorium EDEL using a Burkard 7 Day Recording Volumetric Spore Sampler (Burkard Agronomics TGB). Pollen monitoring stations are parts of the Czech Pollen Information Service, member of the European Pollen Information Service (www.polleninfo.org).

\section{Tests}

Epidemiological data were obtained using two forms - first one filled by parents, the second one by medical staff of the Sanatorium EDEL. In all tested individuals, we collected samples of saliva using a commercial Salivette device (Sarstead, Orsay, France). After two minutes of chewing, the cotton swab was added into a sterile container and centrifuged at $1,000 \mathrm{~g}$ for $15 \mathrm{minutes}$ and stored at $-20^{\circ} \mathrm{C}$. We used identical times (between 8 and $9 \mathrm{AM}$ ) for sampling, so the possible influence of circadian rhythms could be eliminated. Levels of cotinine were measured in saliva by an ELISA kit Salimetrix according to the manufacturer's instruction (Salimetrix Europe, Newmarket, UK). With the suggested laboratory temperature of $20-23{ }^{\circ} \mathrm{C}$, the sensitivity of the method is around $0.15 \mathrm{ng} / \mathrm{ml}$. In all subject, these measurements were done at day 0 and at day 30 . Cortisol levels were also measured by Salimetrix kits (Salimetrix High Sensitivity Salivary Assay Kit) with sensitivity of $0.0007 \mu \mathrm{g} / \mathrm{L}$. Total IgE levels were determined by high affinity fluoroenzymatic assay using an ImmunoCAP 250 analyzator and kits and equipment Phadia (Uppsala, Sweden) with sensitivity of $0.005 \mathrm{IU} / \mathrm{ml}$. All participants absolved at the beginning and at the end 6MWT based on suggested development, including evaluation of additional parameters such frequency before and after physical stress, oxygen saturation, interruption of stress due to the tiredness. These tests were done 2 hrs after the meal.

\section{Statistical analysis}

Statistical significance was evaluated by a pair t-test using a GraphPad Prism 5.04 software (GraphPad Software, USA). An average and standard deviation was evaluated after determination of composition of standard values (D'Agostino, Pearson). In case of non-standard composition, we converted the values into logarithms.

\section{Results}

The glucan-consuming group consisted of 29 children (age 7 - 14 years, mean 9.7; the placebo consuming group used 27 children (age 6 - 16, mean 10.1). Both groups were the same with respect to birth weight or sex (Table 1). The glucan group had $72 \%$ breastfed children; the placebo group had $89 \%$. The differences in duration of breast feeding were statistically not significant and no dif 
ferences were found in average weight or percentage of children with their BMI higher than $95 \%$ or lower than $5 \%$ suggested by CDC. The glucan-supplemented group had slightly elevated allergenic stress by domestic animals allergens. Exposure to passive smoking was indentical in both groups. The percentage of children with $50 \mathrm{~m}$ distance between homes and roads with high traffic frequency were $58.5 \%$ in glucan group and $64 \%$ in placebo group. The number of children with asthma was same in both groups; chronical obstruction of lungs was higher in placebo group. Clinical findings of allergy were $37.9 \%$ in the glucan group, $14,8 \%$ in placebo group. 6MWT values at the beginning of our study are given in Table 1.

The environmental characteristics of our patients did not substantially differ from data published previously [16-18]. The levels of sulphur oxide were almost $4 \mathrm{x}$ higher at the place of residence than in Sanatorium EDEL, the same is true about levels of nitrogen oxide. The highest differences were found in levels of particles, where PM 10 levels at residence reached $50 \mathrm{mg} / \mathrm{m}^{3}$, whereas levels at the Sanatorium are $13.0 \mathrm{mg} / \mathrm{m}^{3}$. Almost identical differences were found in case of PM 2.5 (average $40 \mathrm{mg} / \mathrm{m}^{3} \mathrm{vs} .10 \mathrm{mg} / \mathrm{m}^{3}$ ). The difference primarily all due to the distance from frequented routes, which at the Sanatorium is over $1500 \mathrm{~m}$, whereas more than $50 \%$ of evaluated children lives less than $50 \mathrm{~m}$ from a road with high frequency of automobile traffic (Table 1). Another stress on the respiratory tract is caused by additional contaminants of environment, particularly pollen. The differences between home and Sanatorium levels of pollen were again significant. Table 2 summarized individual contaminants present during March and April.

Cumulation of negative factors affecting respiratory tract is further increased by high exposure of children to passive smoke, which is common in almost $50 \%$ of children. Relatively high indoor pollution is caused by pets, which is in the asthmatic group higher than $50 \%$ (Table 1). As the types of residences are almost identical in both groups (mostly panel housing), both groups had the same risk on indoor contamination. Levels of salivary cotinine, which is an indicator of exposure to passive smoking, are shown in Figure 1. Levels found in the glucan group at the beginning $(0.85 \mathrm{ng} / \mathrm{ml} \pm 0.26)$ and at the end of the study $(0.235 \mathrm{ng} / \mathrm{ml} \pm 0.07)$ are significantly different from the control group $(0.436 \mathrm{ng} / \mathrm{ml} \pm 0.22 ; 0.28 \mathrm{ng} / \mathrm{ml} \pm 0.22$, resp.). The cotinine levels decreased after 30 days of stay at the Sanatorium in both groups, but the glucan-supplemented group showed a much higher rate of decrease. The possible effects of diet can be negligible, as both groups were getting identical food during the whole stay. The total levels of cotinine at the glucan group were strongly influenced by extremely high levels found in three children. These levels were most probably caused by demonstrated multiple exposure to tobacco smoke with three strong smokers in the family.

Figure 2 summarizes the findings of the cortisol levels. At the beginning of our study, the levels found in both groups were statistically identical $(0.45$ and $0.42 \mu \mathrm{g} / \mathrm{ml})$. A decrease in cortisol levels after the 30 day stay was found in both groups, however, the decrease was significant only in glucan group.

Total levels of salivary IgE reached $0.30 \pm 0.39 \mathrm{IU} / \mathrm{ml}$ in glucan group, in placebo group it was $0.21 \pm 0.20 \mathrm{IU} / \mathrm{ml}$. In both groups we observed an increase in salivary IgE levels, but these changes were not statistically significant (Figure 3). Detailed study showed that this increase was most probably caused by seasonal exposure to pollen particles. Evaluation of the 6MWT test demonstrated an increase of physical capacity from 430 to $445 \mathrm{~m}(\mathrm{p}<0.07)$ in glucan group, but no changes in the placebo group (Table 1$)$.

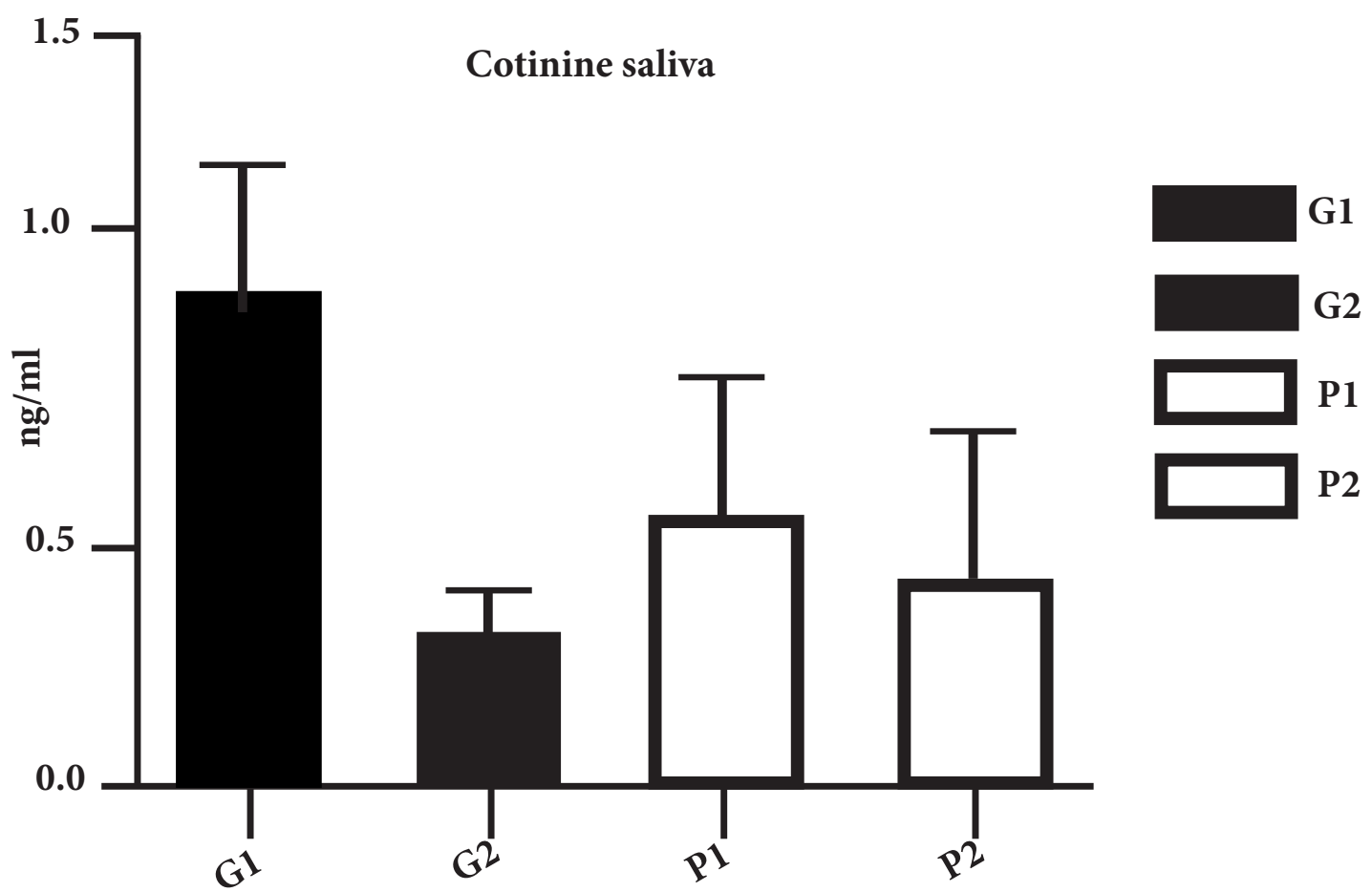

Figure 1: B Effects of 4-week oral administration of glucan (100 mg/day) on cotinine levels in saliva. GL 1 represents glucan group at day 1; GL 2 at day 30. C1 represents control (placebo) group at day 1, C 2 at day 30. Data show statisticall significance between groups. 


\section{Cortisol saliva}

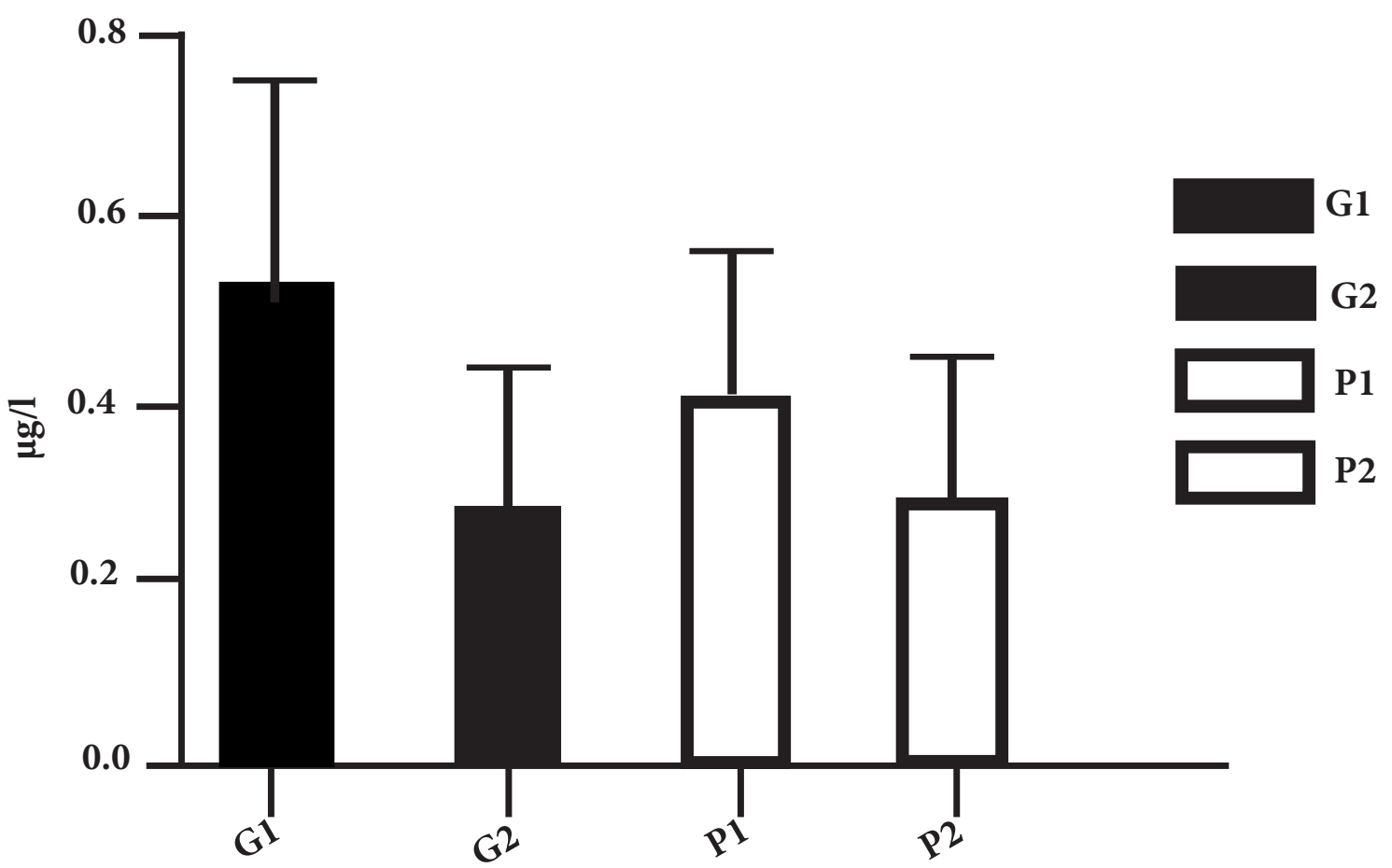

Figure 2: Effects of 4-week oral administration of glucan (100 mg/day) on cortisol levels in saliva. GL 1 represents glucan group at day 1; GL 2 at day 30. C1 represents control (placebo) group at day 1, C 2 at day 30. Data show statisticall significance between groups.

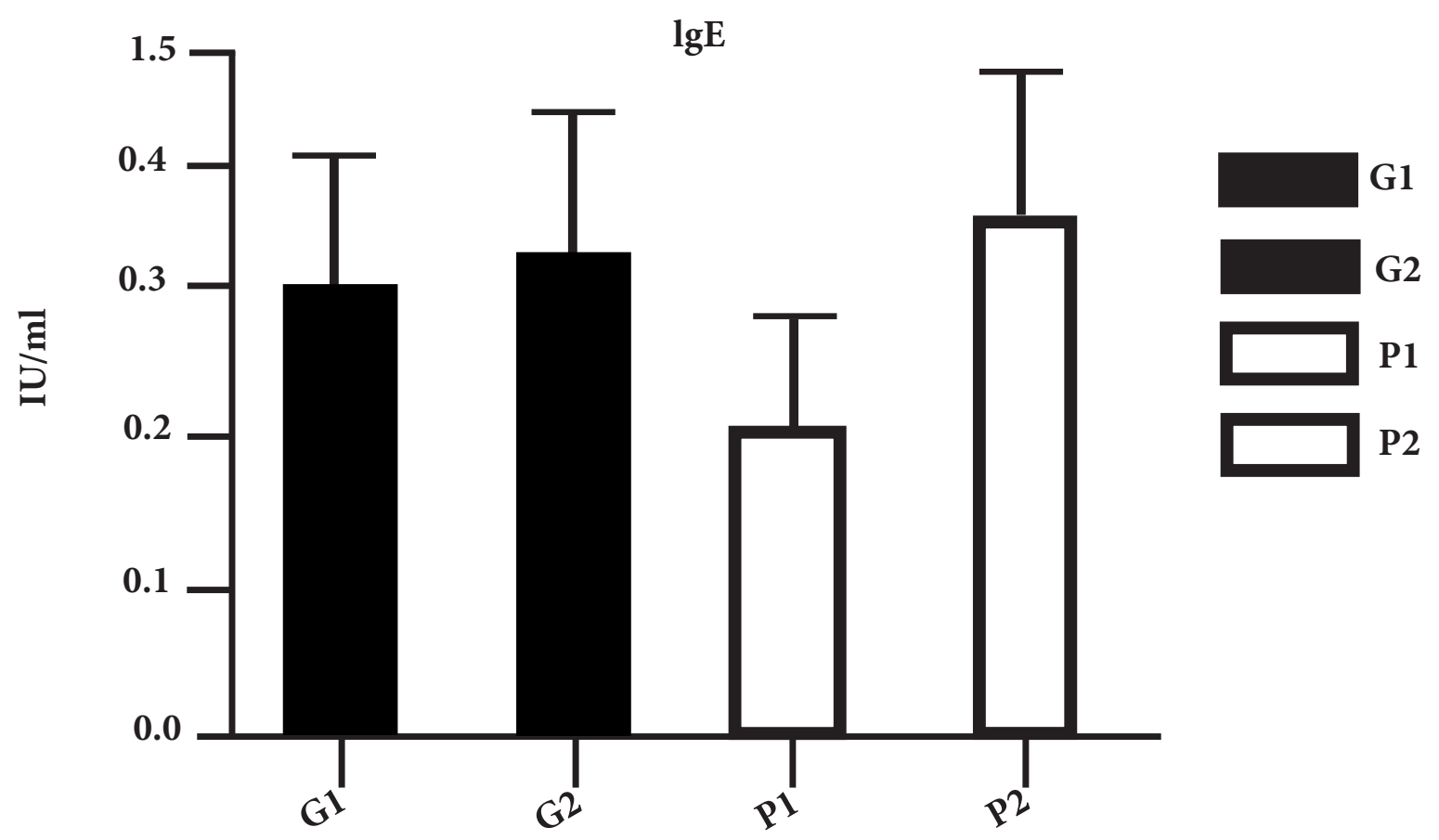

Figure 3: B Effects of 4-week oral administration of glucan (100 mg/day) on IgE levels in saliva. GL 1 represents glucan group at day 1; GL 2 at ay 30. C1 represents control (placebo) group at day $1, \mathrm{C} 2$ at day 30 . Data show statisticall significance between groups. 


\begin{tabular}{|l|c|c|}
\hline & Glucan group & Placebo group \\
\hline Child characteristics & $\mathrm{n}=29$ & $\mathrm{n}=27$ \\
\hline Age (min-max) & $7-14$ & $6-16$ \\
\hline Age Mean (SD) & $9,7(2,0)$ & $10,1(2,7)$ \\
\hline Male sex (\%) & $16(55,2)$ & $15(55,6)$ \\
\hline Female sex (\%) & $13(44,8)$ & $12(44,4)$ \\
\hline Birth weight (grams) & 3404,6 & 3182,7 \\
\hline Breastfed (\%) & 72,4 & 88,9 \\
\hline Breastfed Month Mean & 7,38 & 9,77 \\
\hline BMI (SD) & $18,3(3,5)$ & $18,2(4,4)$ \\
\hline BMI - for - age percentils >95\% & $\% 4(13,8)$ & $5(18,5)$ \\
\hline BMI - for - age percentils <5\% & $\% 2(6,9)$ & $4(14,8)$ \\
\hline Pet keeping (\%) & $15(51,7)$ & $8(29,6)$ \\
\hline Passive smoking (\%) & $15(51,7)$ & $12(44,4)$ \\
\hline Living within 50 m of a main street N(\%) & $17(58,6)$ & $16(64)$ \\
\hline Living within 500 m of a main street N(\%) & $8(27,6)$ & $9(36)$ \\
\hline Living within more m of a main street N(\%) & $4(4)$ & $0(0)$ \\
\hline Allergy (\%) & $11(37,9)$ & $4(14,8)$ \\
\hline Asthma (\%) & $16(55,2)$ & $14(51,9)$ \\
\hline $\begin{array}{l}\text { COPD (chronic obstructive pulmon. disease ) } \\
\%\end{array}$ & $2(6,9)$ & $9(33,3)$ \\
\hline 6 Minute Walk Test I. (SD) & $430(38)$ & $440(85)$ \\
\hline 6 Minute Walk Test II. (SD) & $445(57)$ & \\
\hline
\end{tabular}

Values are absolute/values (percentages)or means (SD)

Table 1: Basic information on tested groups of children

\begin{tabular}{|c|c|c|c|}
\hline \multicolumn{2}{|c|}{ Plant species } & Bohumín & Zlaté Hory \\
\hline Alnus & Alder & 8249 & 1746 \\
\hline Betula & Birch & 10 & 0 \\
\hline Carpinus & Bornbeam & 3 & 491 \\
\hline Corylus & Hasel & 1413 & 114 \\
\hline Populus & Poplar & 1306 & 299 \\
\hline Taxus & Yew & 1184 & 95 \\
\hline Salix & willow & 243 & \\
\hline
\end{tabular}

Table 2: The number of pollen grains (1m3 ) in residence children (Bohumín - Moravia) and Sanatorium EDEL (Zlaté Hory) (March and April 2011)

\section{Discussion}

Currently there is little doubt about the fact that contamination of environment strongly affects the health problems of the whole population, and children in particular [1]. The overall quality of environment has strong effects on development of immune system and on some diseases affecting both mental and physical development $[1,3]$. Environmental stress is reflected in respiratory tract diseases, development of allergies, increase in occurrence of asthma bronchiale and other health problems [19]. The increase in prevalence of asthma bronchiale in highly polluted region of the Czech Republic in last decade (2002-2012) achieved more than $10 \%$ and represents a heavy economical strain for the health industry. The only possible way for improvement of the current state is significant reduction of all aspects adding to the contamination of the environment. An actual solution can be short term limination of exposure to environmental contaminants caused by the locality [19]. The effects of this solution were demonstrated during the Olympic games in Atlanta, were the reduction in automobile traffic caused an decrease in overall sickness. The World Health Organization describes traffic-based contaminants as primary causes leading to the developments of allergic diseases. The 
authors conclude that the distance of the residence to the frequented road represents significant risk factor [5], where living up to $20 \mathrm{~m}$ from heavy frequented street increased the risk of respiratory problems up to 15 percent [3]. In might be important to note that these findings will differ among different countries, which can be explained not only by different age and general state of the vehicles, but also by prevalent type of engine. An increase of environmental pollution in the Czech Republic is influenced not only by high percentage of diesel engines, but also by an average age of cars, which is greater than 10 years. Taken together, we consider it necessary to monitor quantity and development of pulmonary functions that are heavily influenced by distance from traffic. Gauderman and his group found significant changes of pulmonary functions in individuals living closer than 500 meters from roads compared to people living further than 1000 meters [4]. In addition, these damages can often last an entire lifetime. In our conditions, children often spent significant periods of time outdoors; therefore, it is necessary to also calculate the localization of the school. Among children tested in our report, the distance between the school and busy street was more than 100 meters.

Exposure to passive smoke represents an important health stress affecting the development and quality of the immune system. Evaluation of the levels of salivary cotinine represents a non-invasive and highly precise indicator of exposure to tobacco smoke. By measuring the levels of salivary cotinine we can determine the level of exposure and monitor the end of the exposure [20]. The total levels of cotinine are affected by the combination of exposure and the size of the interior, as well as the relationship between the smoker and the passive smoker. The highest levels of cotinine can be found in children exposed to the smoke by mother, whereas the exposure by father leads to the lower levels (probably by forcing the father to smoke outside by non-smoking mother). The relationship between the cotinine levels and tobacco smoke from both smoking parents is clear and our results are in agreement with results obtained in children from countries such as the United Kingdom, Wales or Sweden [20]. Approximately 75\% of nicotine is converted to cotinine, most of all by cytochrome P450 2A6 [21]. The half-life of cotinine is 16 hours, its levels are stable throughout the day and the correlation between the findings in saliva and blood is extremely high. Metabolism of cotinine can be influenced by genetic factors, race, sex, and is usually higher in children exposed to passive smoke than in similarly stressed adults [21]. Higher levels were found in children with asthma bronchiale [21], which our study confirmed. In addition, we pointed out the effects of environmental contaminants on increase of cotinine levels. In these cases the cotinine levels are higher than the 3 $\mathrm{ng} / \mathrm{ml}$ cut-off point (NHANES 1999-2004) distinguishing between passive and active smoking [21]. Information of the effects of passive smoking on children's health, particularly on their pulmonary system, is in families with affected children often overlooked and significant public education is necessary. Based on the forms utilized in our study, only $30 \%$ of the population has any knowledge about the possible effects of passive smoking on induction of asthmatic or allergic diseases. In addition, the full knowledge of these interactions is not totally understood even in the professional population. A Th1/Th2 imbalance induced by smoking is not studied in detail, similarly we do not have enough information about T regulation system in passive smokers.

All this offers one of possible ways as to how to influence health status of passive smokers. It is well known that $\beta$-glucans are strong immunomodulators with positive effects on immunocompetent cells [22]. An optimal application of $\beta$-glucan in individuals with heavy physical stress reduced respiratory illnesses, increased phagocytic and NK cell activity [22]. Several experiments demonstrated that glucan treatment after stress resulted in the decrease of lactate levels, lower activity of creatinine kinase as well as additional markers demonstrating stronger endurance during higher stress [23]. Effects of $\beta$-glucans on activation of macrophages and neutrophils together with their stimulation of phagocytosis, cytotoxicity and antimicrobial activity via activation of specific receptors (such as CR3, Dectin-1, lactosyl or TLR2-6) are well established (for review see [24]) and can be utilized in suppression of stress of our group of children. The reasons why we used a relatively short supplementation are twofold - first, we wanted to evaluate the hypothesis that glucan can help even after short interval, and second the 30 days corresponded to the length of stay in the Sanatorium.

Dynamics of changes in salivary IgE is different based on exposure to passive smoking. Higher original levels were found in children exposed to smoking, which corresponds to the previous findings [2]. When re-evaluated after the 30 day stay at the Sanatorium, we found a small insignificant increase, which was most probably caused by seasonal allergens. This exposure was, compared to residence, significantly smaller, due to the low allergen exposure from lawn surrounding the whole Sanatorium campus.

It is necessary to understand that children evaluated in our study are under the influence of chronic stress of complex etiology (environment, passive smoking, social and economic influences) [6]. Taking out from long term stress resulted in pronounced decrease of cortisol levels, which was most pronounced in glucan-supplemented group. Measuring cortisol during morning hours had no influence on levels of salivary cotinine, known for increased levels during the day. It is known that allergic patients react to stress by increase of cortisol levels [6]. The positive effects of glucan on several types of stress have been already described [8]. Later, the positive effects of glucans on respiratory symptoms in individuals with mood stress [9]. Based on our data, we conclude that immunostimulatory effects of $\beta$-glucan resulted in improvements of medical parameters during and after the medical stay at the Sanatorium $[16,17,25,26]$.

Positive effects of complex curative treatment using $\beta$-glucan are accompanied by increased physical endurance and by significant reduction of negative clinical problems of affected children [27]. These finding are supported by improvements in 6MWT, where the data in the glucan-treated group corresponds with the normal child population of the same age group [15]. 


\section{Conclusions}

The positive effects of complex curative treatment using $\beta$-glucan were accompanied by increased physical endurance and by significant reduction of negative clinical problems of affected children. Based on these data, we conclude that natural immunomodulator $\beta$-glucan significantly improves the overall health of children with chronic respiratory problems caused by environmental stress and/or passive smoking.

\section{Acknowledgement}

This study was supported by the Technology Agency of the Czech Republic TACR TA 0202094.

\section{References}

1. Buka I, Koranteng S, Osormio-Vargas A (2006) The effects of air pollution on the health of children. Paediatr Child Health 11: 513-6.

2. Oryszczyn MP, Annesi-Maesano I, Charpin D, Paty E, Maccario J, et al. (2000) Relationships of active and passive smoking to total IgE in adults of the epidemiological study of the genetics and environment of asthma, bronchial hyperresponsiveness, and atopy (EGEA). Am J Respir Crit Care Med 161: 1241-6.

3. Bayer-Oglesby L, Schindler Ch, Arx ME, Braun-Fahrlander C, Keidel D, et al. (2006) Living near main streets and respiratory symptoms in adults. Am J Epidemiol 164: 1190-8.

4. Gauderman WJ, Vora H, McConnell R, Berhane K, Gillard F, et al. (2007) Effect of exposure to traffic on lung development from 10 to 18 years of age: a cohort study. Lancet 369: 571-7.

5. Morgenstern A, Zutavern A, Cyrys J, Brockow I, Koletzko S, et al. (2008) Atopic diseases, allergic sensitization, and exposure to traffic-related air pollution in children. Am J Respir Crit Care Med 177: 1331-7.

6. Mizawa M, Yamaguchi M, Ueda Ch, Makino T, Shimizu T (2013) Stress evaluation in adult patients with atopic dermatitis using salivary cortisol. BioMed Res Int 2013: 138027.

7. Stenius F, Borres M, Bottai M, Lilja G, Lindbladt F, et al (2011) Salivary cortisol levels and allergy in children: The ALADDIN birth cohort. J Allergy Clin Immunol 128: 1335-9.

8. Vetvicka V, Vancikova Z (2010) Anti-stress action of several orally-given $\beta$-glucans. Biomed Pap 154: 235-8.

9. Talbott SM, Talbott JA (2012) Baker's yeast beta-glucan supplement reduces upper respiratory symptoms and improves mood state in stressed women. J Am Coll Nutr 31: 295-300

10. Benacerraf B, Sebestyen MM (1957) Effect of bacterial endotoxin on the reticuloendothelial system. Fed Proc 16: 860-7.

11. Rigi SJ, Di Luzio NR (1961) Identification of a reticuloendothelial stimulating agent in zymosan. Am J Physiol 200: 297-300.

12. Novak M, Vetvicka V (2008) $\beta$-Glucans, history, and the present: Immunomodulatory aspects and mechanisms of action. J Immunotoxicol 5: 47-57.

13. Novak M, Vetvicka V (2009) $\beta$-Glucans as biological response modifiers. Immune Dis Drug Targets 9: 67-75.

14. Větvicka V (2011) Glucan-immunostimulant, adjuvant, potential drug. World J Clin Oncol 2: 115 - 9.

15. Li AM, Yin J, Au JT, So HK, Tang T, et al. (2007) Standard reference for the Six-Minute-Walk Test in healthy children aged 7 to 16 years. Am J Respir Crit Care Med 176: 174-80.

16. Vetvicka V, Richter J, Svozil V, Rajnohova Dobiášova L, Kral V (2013) Placebo-driven clinical trials of Transfer Point glucan \#300 in children with chronic respiratory problems: Antibody production. Am J Immunol 9: 43-7.

17. Vetvicka V, Richter J, Svozil V, Rajnohova Dobiášova L, Kral V (2013) Placebo -driven clinical trials of yeast-derived $\beta$-(1,3) glucan in children with chronic respiratory problems. Ann Transl Med 26: 1-5.

18. Vetvicka V, Richter J, Svozil V, Rajnohova Dobiášova L, Kral (2013) Placebo - driven clinical trials of Transfer Point Glucan \#300 in children with chronic respiratory problems: III. Clinical findings. Am J Immunol 9: 88-93.

19. Renzetti G, Silvestre G, D'Amario C, Bottini E, et al. (2009) Less air pollution leads to rapid reduction of airway inflammation and improved airway function in asthmatic children. Pediatrics 123: 1051-1153.

20. Abidin EZ, Semple S, Omar A, Rahman HA, Turner SW, et al. (2011) A survey of schoolchildren's exposure to secondhand smoke in Malaysia. BMC Public Health 11: 634-45.

21. Avila-Tang E, Al-Delaimy WK, Ashley DL, Benowitz N, et al. (2013) Assessing secondhand smoke using biological markers. Tobacco Control 22: 164-71.

22. Bergendiova K, Tibenska E, Majtan J (2011) Pleuran ( $\beta$-glucan from Pleurotus ostreatus): Supplementation, cellular immune response and respiratory tract infections in athletes. Eur J Appl Physiol 111: 2033-40.

23. Xu C, Lo IM, Cui SW, Hu X, Fan M (2013) Effects of oat $\beta$-glucan on endurance exercise and its anti-fatigue properties in trained rats. Carbohydr Pol 92: $1159-65$.

24. Vetvicka V (2013) $\beta$-Glucans as Natural Biological Response Modifiers. Nova Science Publishers, New York.

25. Richter J, Svozil V, Král V, Rajnohova Dobiášova L, Stiborova I, et al. (2014) Clinical trials of yeast-derived $\beta$-(1,3) glucan in children: effects on innate immunity. Ann Transl Med 2: 1 - 6.

26. Vetvicka V, Vančíková Z (2013) 1,3-glukan a alergie. Alergie 4: 6 - 8 .

27. Nieman DC, Henson DA, McMahon M, Wrieden JL, Davis JM, et al. (2008) $\beta$-Glucan, immune function, and upper respiratory tract infections in athletes. Med Sci Sport Exercise 40: 1463-71. 


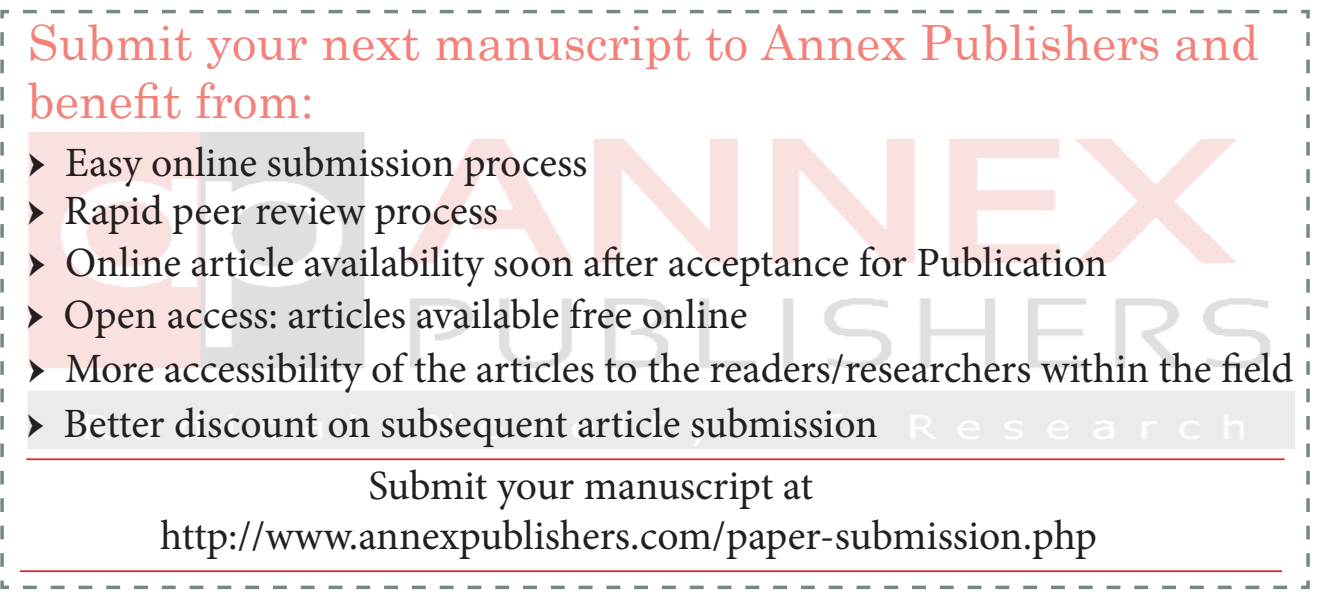

